\title{
Natural Law as Subjective Dimension \& Representative Form
}

\author{
Yifeng Wen \\ The Research Center of Cantonese Culture, Guangzhou University, Guangzhou, China \\ Email: wenyifeng1968@sina.com
}

How to cite this paper: Wen, Y. F. (2018). Natural Law as Subjective Dimension \& Representative Form. Open Journal of Philosophy, 8, 1-7.

https://doi.org/10.4236/ojpp.2018.81001

Received: November 27, 2017

Accepted: December 26, 2017

Published: December 29, 2017

Copyright $\odot 2018$ by author and Scientific Research Publishing Inc. This work is licensed under the Creative Commons Attribution International License (CC BY 4.0).

http://creativecommons.org/licenses/by/4.0/

\begin{abstract}
The aim of science is to discover natural law, or to explain the consistency of things that we know through our senses. Whereas the essence of sense and natural law themselves still remain many problems waited to explore clearly even in today. By logic analysis and review some theories, especially phenomenology, this paper reaches conclusion that natural law in essence is subject's dimension and subjective logic form which can spread things out, objectively define things and represent them in mind. The scientific model is a logical metaphor that blends the concepts of common experience with priori form.
\end{abstract}

\section{Keywords}

Science Philosophy, Natural Philosophy, Phenomenology, Logic Form

\section{Introduction}

The goal of science, as our known, is to discover natural law by experiment and observation; or as Whitehead (1919) said in The Concept of Nature, the first task of the philosophy of science should be the general classification of what is revealed in our sense-awareness sand sense-perception, and to explain the consistency of things that we know through our senses. Whitehead held that natural philosophy is to analyze how these different natural elements relate to each other. In other words, the question of natural philosophy is to discuss the relationship between what is known and not to be asked: what is in the mind? What is in nature? It is means that we should not ask the entities or substance behind everything, but be more modest to use propositions that descript things revealed to us. Or as Newton (1686) said in The Mathematical Principles of Natural Philosophy and His System of the World, what he had done is just trying to explain natural phenomena and the forces of nature on the mathematical law, for the 
force in itself we have no knowledge, so until now, all philosophers ended in failure to explore nature.

\section{Analysis on Newton's Work and Einstein's View}

Based on Newton's work, we can see that Newton emphasized empirical observation and experimental method. But in fact, most of the important laws of nature that he discovered are result of logic, not empirical observation. Here, we take the third law of Newtonian mechanics as example for analysis. Newton said: acting power is equal to reacting power, which only said out a half truth. The reason for this proposition be regarded as general principle beyond any individual sense or perception is that the existence of acting power depending on its opposite, i.e. the existence of reacting power, for this reason acting power being equal to reacting power is inevitable proposition in terms of logic. But if acting power is equal to reacting power only in converse direction, it cannot motivate anything, because acting power causes material movement according to its acting direction, while reacting power is equal quantity to acting power only inverse direction, it also can cause the material moving inverse direction, hence two direction movement became equal effect, since acting power already indicated the direction of material movement, thus it must greater than reacting power, that is to say, the direction and quantity as essence definition of power, and the acting power and reacting power as two substantial names they must not only be inverse direction also cannot be equal in quantity. The contradiction about acting power and reacting power not only announces that the mechanic determinism is not truth (Wen, 2011), also demonstrates that Newton's third law of mechanics is not an empirical observation, but a priori logic. If we are doing the same analysis for the first and second laws of Newtonian mechanics, also reach the same conclusion: all of them are not directly empirical fact, but rather some priori logical proposition about the meaning of straight, even, inertia, stationary, movement and power, or in terms of Kant's theory just as priori synthetic judgment. Further we take Newton's law of universal gravitation as example, even Newton himself realized with humility that it is not an ontological statements about the universe; he just give some Mathematical Principles about nature, for the origin of the force in itself he cannot say anything. Today the Law of Universal Gravitation can properly be regarded as a simplified model to comprehensively describe universe phenomenon. Newton's logic is simple in terms of that it is based on some isolated concepts extracted from daily experience.

A core idea of Einstein's theory of relativity is put physical concepts together in an organic way which seemly isolated in Newtonian mechanics. Its striking achievement is regard as that it solves some problems of Newtonian mechanics, such as the action at a distance of gravity and predicted the phenomenon of light bending. While the most important contribution of Einstein's theory of relativity in essence is a logical, that is to say, he organic unify the physical concepts with more consistent meaning than Newtonian mechanics, the efforts of which also 
reflected in his pursuit of the unified field theory. Now the philosophical question to be raised here: what is the true meaning of the scientific law? What is the true meaning of logic? Or what is true meaning of simplified model in terms of today science philosophy? To those kinds of problem it cannot leave the discussion of phenomenology?

\section{Phenomenology}

On the Tarner Lectures in the philosophy of science, Whitehead begins with a critique of generally accepted ideas about substance, space, and time. To assume that matter is the basis of reality, he insists, is a longstanding error, whereby a metaphysical abstraction has been misinterpreted as a concrete reality. Instead of positing matter as the substratum of the universe, Whitehead argued for the "event" and the "process of becoming" as the starting points for analyzing reality, in this point he appreciated Einstein's view. He felt this "organic" interpretation was closer to our direct, everyday experience of attributes and their relations than the abstract notion of matter assumed by philosophers and scientists for so many centuries. Whitehead's emphasis on direct sense-awareness stimulated phenomenological thinking.

When Einstein said that there must have an external nature world is the premise for physics. This opinion not only tell us that the true meaning of basic concepts of physics in fact is a great mystery, also make us back to Van Orman Quine's (1953) question about the ontology of science concepts. Whether physics concepts are convenient conceptual tools in the sense of pragmatism, or some kinds of ontological statements? What is ontology really meaning? Modern philosophy, especially Husserl's phenomenology put forward a new discussion on the topics of "intuition", "intention" and "meaning". Husserl (1900) proposed subject's "intention" as the origin of meaning and paid more ontological status for phenomenon.

In science philosophy it has been a puzzle problem of division between sense and reason, and subjective sense versus objective knowledge. Phenomenology put this philosophical problem to focus. The concept of physics such as "mass, energy, force", as well as "time and space", what they really mean? Willard Van Orman Quine summed up that problem as opposition between "phenomenology" and "physics". Quine confirmed his phenomenology tendency. He said: in a variety of concept structure "it has that one namely called phenomenology requiring epistemological priority", because phenomenology is the most economic set of concept "suitable for reporting direct experience one after another", "the things belonging to that structure... are feelings or reflections of individual subjective events". As phenomenon is the object of direct experience and directly existence, and not being set up or introduced, is prior in epistemology and more fundamental. Physical object is not directly given things in experience, but as a "convenient intermediary objects" was "introduced", is a kind of contracted setting things in order to simplify theory. In epistemology physical objects are sim- 
ilar with the gods of Homer epic, all of them being "myth" and "fiction", but it just as a structure with easy treatment of flow experience proved more effective than other myths. If agreeing with Quine's said, the meaning source of physics concept and its objectivity become serious problem. In order to solve this problem, Carnap in Logic Structure of World tries to reduce all statements about world to that of direct experience, i.e., from the basic concept relations of original experience to define all other concepts, so putting whole world into "rational reconstruction". Quinn disagrees on this reduction. In On What Things Exist he held that to translate all statements about physical objects through no matter how complex and circuitous way into language of phenomenology is still actually impossible. Quine emphasize that although the concept structure of physics can include the phenomenon "truth" and sense material as scattered part, but sense experience in there belong to, or attach to the physical objects, and lost their basic and prior position on epistemology, that is not acceptable. Therefore, Quine in a manner of pragmatism reached a conclusion: ontology is not about the issue of facts, but that of scientific choice with convenient language form, concept system and structure. Whereas Quine went further according to phenomenology approach no more but into another dead end. In 1953 in On Psychological Thing he flatly declared that the concept of pure sense materials is an extremely empty abstract. Again he confirmed "the paradigm of nominalism is extremely difficult".

Sense versus reason (structure form) which is prior that is a fundamental problem with dispute between nominalism and realism throughout history and also a key issue related with science philosophy. On this question Kant's famous discusses can give us some inspired idea. He said: if without understanding form sense is blind and if without sense the understanding form is empty. That is to say, in Kant's opinion, sense and understanding form are two basic factors for formed experience, and cannot be reduced by each other. It is truth that senses have not a question of true or false, namely no objectivity. We can easily imagine that maggots feel excrement not same with that of human, and persons of achromatopsia have different views of color from us. To be more absolute, I will never be able to prove what I feel red is not just you experience of green. Therefore, the objectivity of judgment is needed to resort to a structure form. But this has not really cut into topic; the aim of this discuss is not just about the first property of matter or the second property of matter, but an issue of ontology. Here give a demonstration to illustrate this issue: by our own memories we can image and analogize a situation-baby cry and smile, but they don't know crying and smiling by themselves. What reason is behind? This is because the baby as same as animals having sense response, but no such as "time, space" and other structure form to spread and represent it out, i.e., can't take perceptual reflection, which is just the very dilemma of extreme nominalism. So we draw conclusion: the form structures are not only the prerequisites of objectivity, but also are the prerequisites for human experience in self. Kant said: a priori synthesizing is 
precondition for experience can being an experience. Now the rest of problem is how do we can understand these structure forms not being from sense? Also it is like such question as geometry apriority?

There is no such pure perceptual experience (or phenomenon) which has no structure form, that is to say, no matter how structure form is a priori prerequisite for experience in the light of Kantism. Hegel's logic followed this line of thinking. Instead of looking law in outside nature world, Hegel look for law in our mind, and he build a complicate logic for describing whole world. However, Hegel's logic application conducted a lot of deduction obviously not conforming to experience. His natural philosophy has many imaginary conclusions such as about the nature of planets. What is Hegel's failure? Even we put aside inevitable limitative nature of logic constructed by human being, "logic" itself is just a percept and reason form for spreading sense experience out and representing it in mind, but not the origin of the sense itself. "Sense", or according to Edmund Husserl more full meaning term, "phenomenon", come from where? As well as other question "form" come from where?

Husserl points out: geometry existence is not psychological one, i.e., not a personal thing in individual consciousness existence. It is to "any person" (to real or may be geometrician, or people who understand geometry) being objective exists. Because here involved "concepts" objectivity. Whereas emotional expression has a kind of time and space with special process in the world, which is like all concrete events or specific objects, but such be called “'object of idea' as spiritual form itself was not that case." However, the flesh nature of language from pure inner subjectivity by what manner starts to produce objective thing? Therefore, all thinkers concerning this problem reach a similar conclusion: idea as transcendental subjectivity achieves its objective existence, i.e., understanding idea must rely on existence of spiritual world. According to this thought, we can distinguish individual experience from understanding idea or form. In terms of personal perception linking to subjective experience, the idea or form is a common structure providing individual experience an understandable description. According to Husserl's saying, the transcendence of idea is not only for personal, and also for cultural. So although world view is also an "idea", but it is in limited among individual life...the world view for each times is different... instead, scientific "idea" transcending time...science is a mark of absolute and without time (Derrida, 1962).

In Husserl's view, scientific idea is seemly limitlessness. In fact, geometry and science were destined to run their head against a stone wall when they deal with unlimited. We can't forget Kant a famous assertion in Critique of Pure Reason: because reason is antinomy by used as description of transcendental entity, its utility can only be limited to form common experience. Reason (or form) in direct sense is without foundation, yet rational propositions in judge transcendental entity are antinomy fantasy, such as the antinomy of time/space's limit or limitlessness. Geometry also can't forget its antinomy in its foundational concepts 
of "linear" and "circle", which demonstrated by irrational figure " $\pi$ ".

\section{Ontology}

Now it is reach a conclusion: the time/space is just subjective form, not substratum reality. Inspired by this, as aforementioned, the antinomy between two definition of mechanic interaction in terms of acting power equal to reacting power and acting power greater than reacting power is just subjective conception dimension, i.e., something like time and space is subject's form. Yet just as subjective form, they form the objectivity of nature phenomenon. In this point, we review some most important philosophical idea about nature. Newton's absolute concepts of time/space and mechanics remain unconsciousness for their antinomy, and mistakenly putting those as nature attribute. Hegel is blind for the origin of sense which cannot be reduced to logic form. Whereas Whitehead unconsciously has an assumption of objective sense-awareness, not realize that the objectivity of sense depend on concept as form. In Husserl's phenomenology, those problems are deeply reviewed, and put forward subject's intention as meaning base for phenomenon, and he realized that the objective world is constructed by human practice and consciousness, which in some sense have no absolute meaning, in this point it like the idea of Pragmatism philosophy.

Pragmatism philosophy expressed an essence view that rational truth is cannot do without practical purpose. Now both of rational truth (reason) and perceptual truth (cognition) based on experience reality, what difference is between them? That lies not in so-called difference between primal experience and abstract form. As discussed above, so-called original experience or sense without comprehensive structure form does not exist. Whether practical purpose or subjective Intention they need form, also need meaning for sense or as aim. "Intention" in terms of Husserl's phenomenology is an ambiguity combined and obscured concept; it have the meaning of subjective form and also have a meaning as the origin of sense. We can still ask "intention" origin from what? To answer this question, Schopenhauer's "will" is a useful concept for reference. Will is primitive power of subjectivity. Based on above discussion, we further set difference between "survival will" and "free will" as two basic categories. The survival will as a metaphysical basis is source of sense and give sense meaning which often being a condition of sub-consciousness, and just in this sense, the "material" is just logical equal to non-consciousness in terms of phenomenology. The free will as metaphysical basis is source of form, and its essence is subjective dimension being associated with subject's representing ability and consciousness. Cognition is to know as direct perceive experience completed by compound effect of survival will which produce sense and free will which produce intellectual form. Because the subjective form such as time/space and reason can able us divorced from current direct experience which animal can never do, therefore we can see that the form is not decided by sense, on the contrary the sense depend on form to represent it to mind and to realization of it. 


\section{Conclusion}

Sense has no objective meaning, like above mentioned the different senses to excrement between human and maggot reflected different survival (will) needs existed in different species and individuals. Objectivity depends on subject's form put thing in a common structure. Whereas the subject's form including such as time/space and reason is in essence antinomy, and just this antinomy in itself includes a tension and dimension that entail human's priori free to represent sense in mind. Logic is the construction of subject's form. Material or nature as exogenous origin of sense is equal to endogenous non-consciousness phenomenon in logic. Because any phenomenon depends on the logic forms for them to be represented in subject's mind, and those forms are essence antinomy, thus they are transcendental entities, not have substance in reality in terms of our common sense. The aim of science is by logic explain our common sense, with the inner antinomy of our logic, so the science in the end must meet the chaos not only in terms of entropy (Prigogine \& Stengers, 1987), also at the meaning of ancient Greek mythology: the Chaos is the original God of the universe. After all, if we think perfect logic as an unattainable ideal, then the scientific model is a logical metaphor that blends the concepts of everyday discrete experience with some transcendental forms.

\section{References}

Derrida, J. (1962). The Introduction of Husserl's “Origin of Geometry”. Paris: France University Press.

Husserl, E. (1900). The Shorter Logical Investigations. In J. N. Findlay (Ed.), Logische Untersuchungen (2nd ed.). London and New York: Taylor \& Francis Group.

Newton, I. (1686). The Mathematical Principles of Natural Philosophy and His System of the World, Berkeley, CA: University of California Press.

Prigogine, I., \& Stengers, I. (1987). Order Out of Chaos. Shanghai: Shanghai Translation Publishing House. (In Chinese)

Van Orman Quine, W. (1953). From a Logical Point of View. Cambridge, MA: Harvard University Press.

Wen, Y. F. (2011). The Fundamental Conception and Theory of Natural Philosophy: A Mega-Theory of Green Building and Eco-Homeland. Applied Mechanics and Materials, 71-78, 4701-4709. https://doi.org/10.4028/www.scientific.net/AMM.71-78.4701

Whitehead, A. N. (1919). The Concept of Nature. Cambridge, MA: Trinity College. 